\title{
AMERICAN INTERNATIONAL RELATIONS AND SECURITY PROGRAMS FOCUSED ON CHINA: A SURVEY OF THE FIELD
}

\author{
Submitted to \\ Carnegie Corporation of New York \\ by the
}

National Committee on United States-China Relations (NCUSCR)

\author{
NCUSCR Survey Team: \\ Jan Berris \\ Johanna Costigan \\ Margot Landman \\ Rosie Levine \\ Jason Togut
}
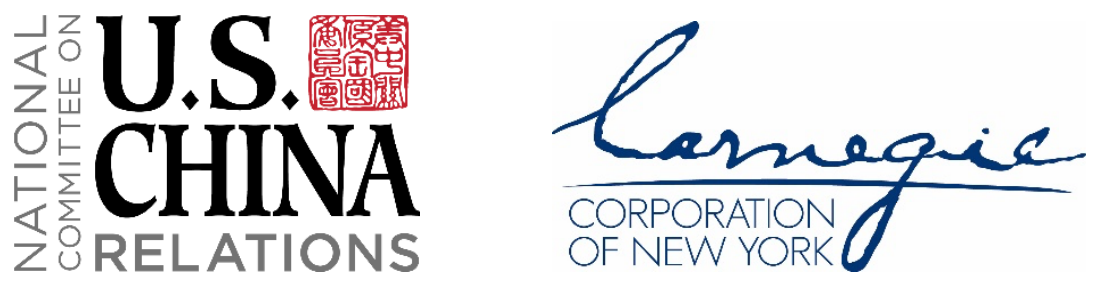


\section{TABLE OF CONTENTS}

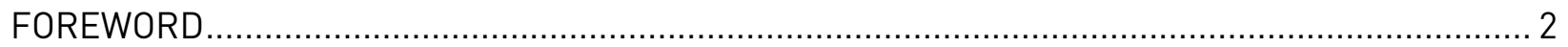

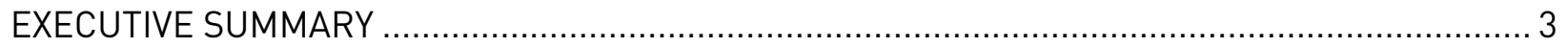

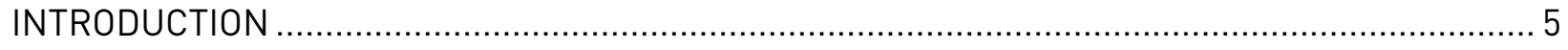

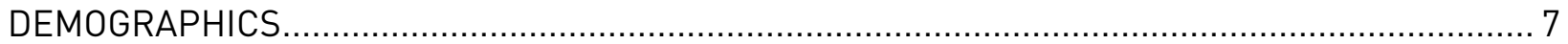

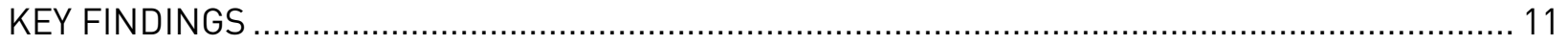

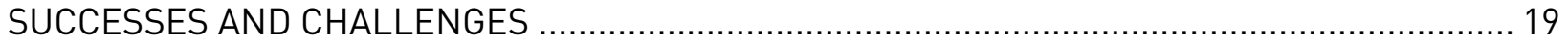

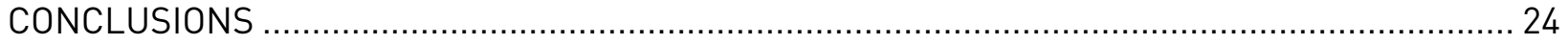

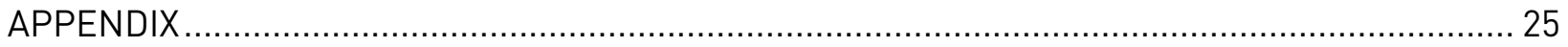




\section{FOREWORD}

Over the past 25 years, the National Committee on United States-China Relations (National Committee) has written five survey-based reports that provide an overview and analysis of China-related international relations and security issues at American academic centers, think tanks, and NGOs. They were conducted at the behest of U.S. foundations and remained internal documents. Believing that these reports would be useful to a wider community, the National Committee is very pleased that a shortened and anonymized version of the latest of these reports, American International Relations and Security Programs Focused on China: A Survey of the Field, is being published by Carnegie Corporation of New York.

Naturally, each report is a snapshot of a specific moment in time, capturing the thoughts and attitudes of the respondents - specialists and scholars in the complex field of China studies. Although this latest report is being published in August 2021, the survey on which it is based was taken in December 2020 and is very much "of its moment" - during the final days of the Trump administration and an ongoing pandemic.

Like its predecessors, this report can be used to understand the current state of the field; to make some educated guesses about the future of China studies; to inform scholarship, public policy decisions, and the general public's desire to know more about China; and to pinpoint the gaps in the field that need to be overcome.

A terrific National Committee team worked on this project: Senior Program Officer Rosie Levine did an extraordinary job of conceptualizing the plan and managing the process; Johanna Costigan, a freelance writer (and former National Committee intern) provided superb writing skills, mastery of the subject matter, and the wonderful ability to keep calm in the face of three very tough editors; Program Assistant Jason Togut did a great job helping determine the institutions and individuals we would survey, as well as figuring out how to best capture the data in graphic form; Deputy Vice President Margot Landman's excellent editing skills contributed to a better final product; and Senior Operations Manager Carly Biondi and Program Operations Manager Alex Guido were extremely helpful in building the report's architecture and technical structure. Huge thanks and kudos to all.

Our thanks also go to Carnegie Corporation of New York for its faith in the National Committee and for entrusting us with this project. Lastly, our deep appreciation to the survey respondents who took the time to reflect so thoughtfully and honestly on their current work and the future of the relationship.

\section{Jan Berris}

Vice President

National Committee on U.S.-China Relations 


\section{EXECUTIVE SUMMARY}

In December 2020, the National Committee on United States-China Relations (NCUSCR) received responses from 82 think tanks, academic centers, and NGOs to a survey commissioned by Carnegie Corporation of New York assessing the state of China-related international relations and peace and security programs in the United States. The results present a snapshot of the field in an era of global disruption, instability, and growing Sino-American tensions, when the surveyed organizations have critical roles to play in increasing expert, policy-level, and public understanding of the bilateral relationship and its broader implications.

At the time the survey was conducted, the COVID-19 pandemic had killed over 1.4 million people and the U.S.-China relationship, already deteriorating for years, had worsened as each government blamed the other for its poor response to the coronavirus. In addition to the Chinese government's actions in the South China Sea, Hong Kong, and Xinjiang, tensions over trade and pandemic management prompted a growing bipartisan, anti-China turn in U.S. policy and rhetoric.

The rapid downward spiral of U.S.-China relations has politicized the field, limited scholars' ability to conduct productive research, and contributed to the rise of anti-Asian racism in the United States. The hawkish dominant narratives on China have made it more difficult for people to express balanced views lest they be labeled excessively pro-China. At the same time, in the wake of the arbitrary detentions of Michael Kovrig and Michael Spavor (Canadian citizens who have been in Chinese detention since December 2018), some respondents expressed concern for their own safety in China.

Survey responses make clear the U.S.-China relationship has experienced structural shifts that no single policy change or executive order can undo. Scholars and practitioners will have to find ways to navigate increasingly hostile environments in and between both countries, effectively manage risks, and endure increased pressure and scrutiny on their output. As American focus on China continues to expand, however, U.S.-based China-focused scholars and practitioners face increasing opportunities, challenges, and responsibilities.

Key Finding 1: Demand for China content is growing in the United States, leading to an increase in opportunities for think tanks, programmatic institutions, and academia, along with a shift toward more public-facing work in the latter community.

Key Finding 2: In China, domestic tightening has limited information flows, including access to data and the ability to conduct in-country research and interact with Chinese counterparts safely and effectively, influencing the topics that can be addressed productively.

Key Finding 3: While often in response to specific Chinese actions and policies, the Trump administration's management of the relationship placed American foreign policy institutions and individual scholars focused on China in the crossfire, limiting their ability to successfully conduct research and programming.

Key Finding 4: The downturn in the bilateral relationship has politicized work on China and constrained organizations by severely polarizing discussion of China and Sino-American relations, resulting in a diminution of the quality of the discourse in both countries.

Key Finding 5: In the current U.S. geopolitical environment, many China-related topics are viewed through the lens of security, both within and outside academia. As a result, China has often been reduced to a target in U.S. domestic rhetoric, rather than a complex subject of multidisciplinary study. 
Respondents also reported other challenges, both individually and writ large, including financial limitations, navigating a limited number of funders with a range of priorities, a glaring lack of diversity among practitioners in the China studies space, and the "pipeline issue" of providing opportunities that keep students involved in China studies. Despite these obstacles, the respondents also underscored the continued value of conducting cutting-edge research, training the next generation of foreign policy professionals, and providing insights in digestible ways to broad audiences. They also identified major research gaps on the frontiers of the field, such as:

Emerging Technologies, including the role of artificial intelligence, effects on cybersecurity, Chinese science and technology policy, and the implications of technological decoupling and/or localization.

China's International Economic Engagement and its continuing trade expansion, U.S.Chinese economic interdependence and interests, the stability of the global economy, and the role of the economy as a tool of Chinese statecraft.

Data Access and the ability to analyze original Chinese-language documents, datasets, articles, commentary, and speeches, as well as the need for open-source translation of these documents for foreign policy analysts not fluent in Mandarin Chinese.

Nontraditional Security Studies such as environmental security, public health, and human rights, which are too siloed and require better integration in U.S. foreign policy and peace and security conversations.

Understanding China's Political Intentions, both internationally through efforts to "export" its model and shape international regimes, and domestically as viewed through Chinese Communist Party (CCP) dynamics and decision-making under President Xi; China's bilateral relations with countries other than the United States, especially Russia and India.

Other areas needing attention include nuanced study of Chinese ethnic minority communities and governance, a "return to Sinology" (revival of area studies), research into the CCP's approach to diplomacy beyond military-to-military relations, and training on how to manage risks introduced by an increasingly repressive Chinese government.

The key findings and identified research gaps reflected in this report paint a picture of heightened interest in advancing understanding of, and between, the United States and China, amid a challenging environment of geopolitical tension with spillover effects on China-related research, analysis, and programming. Above all, they also underscore the critical need for persisting in these efforts given the stakes involved in the most consequential geostrategic relationship of the 21 st century. 


\section{INTRODUCTION}

At the request of Carnegie Corporation of New York (CCNY), the National Committee on United States-China Relations (National Committee) has produced a report covering China-related international relations and peace and security programs in the United States. It is intended to assist the Corporation in understanding the current state of the field, summarizing the geopolitical developments that have shaped the field in recent years, and pinpointing important gaps in research. The National Committee sent a survey to 125 institutions in December 2020; this report is based on the 82 responses $^{1}$ that were received, in addition to comments from 53 China experts contacted during the initial stages of research, and feedback from three reviewers. $^{2}$

In addition to a needs assessment for the Corporation, the report provides an evaluation of the primary challenges faced by American China-focused programs since the last time the National Committee conducted a somewhat similar report about 10 years ago. ${ }^{3}$ In the intervening period, geopolitical developments in and between Beijing and Washington, D.C., have affected the work of U.S.-based China scholars and institutions. China's rapid military modernization, technological advances, and meteoric economic growth loften subsumed under the omnipresent term "China's rise") are perceived as an existential threat by some who are wary of China's role on the global stage. Other analyses tend to focus on specific areas of concern: the CCP's coercive legislation and actions in Hong Kong and Xinjiang, more aggressive foreign policy, adoption of an international NGO law that constrains various exchange activities, and greater restrictions for Chinese and foreigners on many forms of research, intellectual exchange, and public discourse.

On the American side, the last decade has also seen the development of an increasingly adversarial stance toward the People's Republic of China (PRC). The souring in the relationship is in part the product of bipartisan hawkishness on China policy; it both preceded and transcends the Trump administration. As one reviewer wrote, "There is general consensus that the relationship was already trending downward before he took office, and got worse as both sides failed to take steps to reconcile their differences." Under the Trump administration, this was manifested through a trade war, the Justice Department's China Initiative targeting Chinese researchers and academics, increased anti-Chinese racism, and the elimination of the Peace Corps and Fulbright China programs.

Both countries have engaged in a tit-for-tat race to the bottom - evident in maneuvers such as restrictive visa policies and the sudden closing of the Chinese Consulate in Houston leading to the closing of the U.S. Consulate in Chengdu. These factors, along with several others, have contributed to creating a changed landscape for those who work in the realm of China studies and peace and security.

\footnotetext{
1 The full list of organizations that responded to the survey may be found in the appendix.

${ }^{2}$ All three reviewers also filled out the survey on behalf of the programs they oversee, and are thus also included in the 82 respondents.

3 "American China-focused programs" were defined as academic and other not-for-profit organizations based or headquartered in the United States with a "critical mass" of specialists or programming relevant to the topics of this report. Programs or institutions with occasional programming/research or only one or two researchers focusing on relevant topics were not considered.
} 


\section{Methodology}

To ensure that we captured both established institutions and those new to the field, we reassessed the list of organizations we had previously surveyed, adding important organizations that have emerged in the past decade and eliminating those that no longer exist. We then consulted a wide range of scholars and specialists in relevant fields to identify organizations we may have missed. This outreach targeted both senior China hands as well as emerging voices. We utilized a working definition of "security" that goes beyond the traditional foreign policy parameters and includes transnational issues such as climate change, technology, public health, and human rights - thus expanding the types and number of institutions contacted. To ensure a comprehensive list, we talked with a few key scholars in each of these fields about which organizations to include. The institutions surveyed are diverse not only in the type of work they do, but also in their structure le.g., stand-alone institutions, part of a parent organization, independent but embedded within another organization) and funding mechanisms.

\section{Biases and Limitations}

Established in 1966, the National Committee has played a key unofficial role in the SinoAmerican bilateral relationship and in convening China-focused organizations throughout the United States. Our solid understanding of U.S.-China relations and personal connections to leading individuals in the field were strong assets in the survey process. However, given our history and long relationships with the more established institutions, the National Committee also has an unavoidable bias toward these groups, reflected, for example, in our background knowledge of ongoing programs or research, and in our ability to send personalized reminders and conduct detailed follow-up.

One major challenge in writing the survey questions was the unique set of circumstances all organizations faced in December 2020 as a result of COVID-19. We attempted to separate pandemic-related issues from organizations' regular work by devoting one section to a series of questions focused solely on the impact of COVID-19. The aim of isolating these effects from other challenges or opportunities was to prompt respondents to think beyond the time frame when their work would be directly affected by the pandemic. For many, however, imagining a future after the pandemic was not easy.

The results make clear that COVID-19 affected organizations differently; those surveyed indicated a range in both the degree of impact and the extent to which the pandemic will continue to affect their work. Since the goal of the survey was to gain an understanding of the typical practices of each organization, we tried our best to prevent the fact that we were gathering information at a very atypical time from becoming an obstacle. However, disentangling pandemic responses from other factors in the relationship presented a challenge to respondents, and thus to analyzing the responses. In addition to logistical and funding impediments brought about by the pandemic, COVID-19 is an external event that has further shaped the U.S.-China relationship and has had a direct impact on research and programmatic opportunities in the field. 


\section{DEMOGRAPHICS}

Each of the 125 organizations we selected received a questionnaire via email with 33 questions divided into the following sections: Primary Contact Information, Organizational Information, Impact of COVID-19, Focus and Activities, Staff and Budget, Geopolitical Landscape, Successes and Challenges, and Organizational Landscape. Some conditional questions became available to respondents based on their selections. The following charts illustrate some basic information about the 82 institutions that responded.

\section{Figure 1: What best describes your parent institution?}

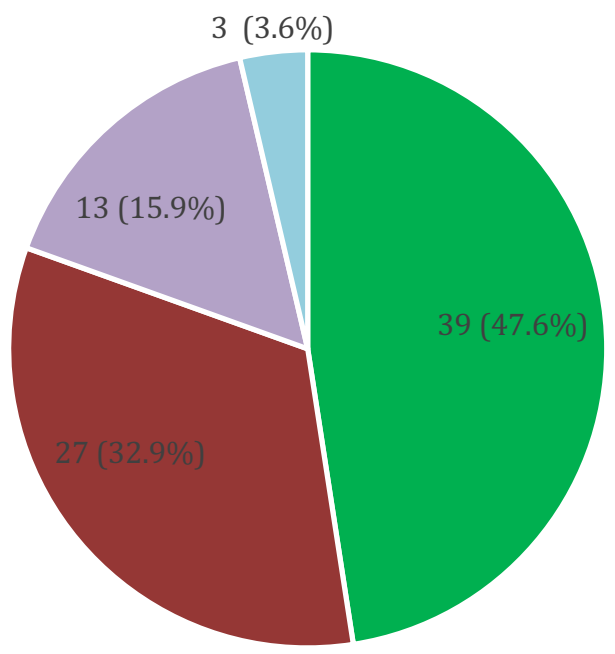

- College or University

- Think Tank

- Programmatic nonprofit/NGO

\section{Figure 2: Activities ranked by priority level}

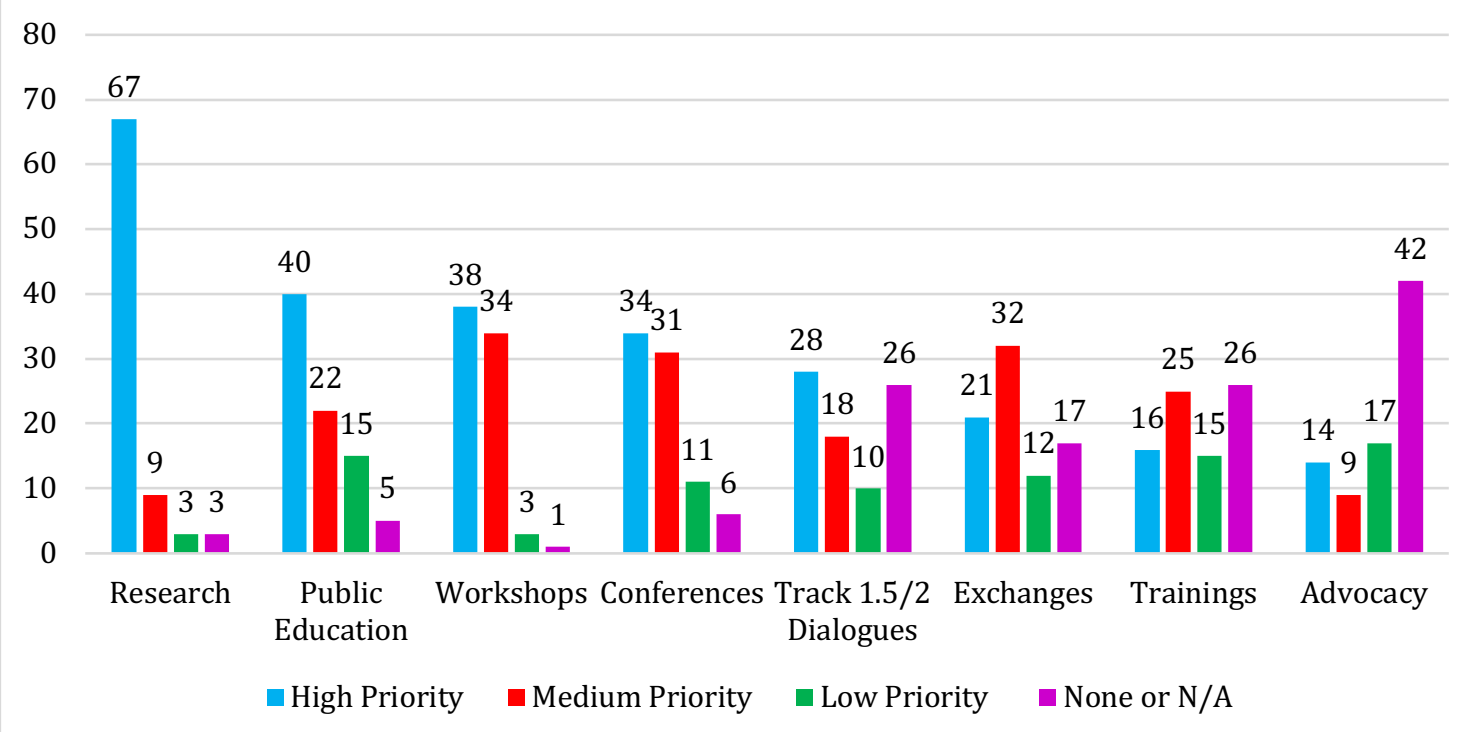


Figure 3: Has the number of staff/affiliated personnel related to your program changed significantly in the past three to five years (for reasons not related to COVID-19)?

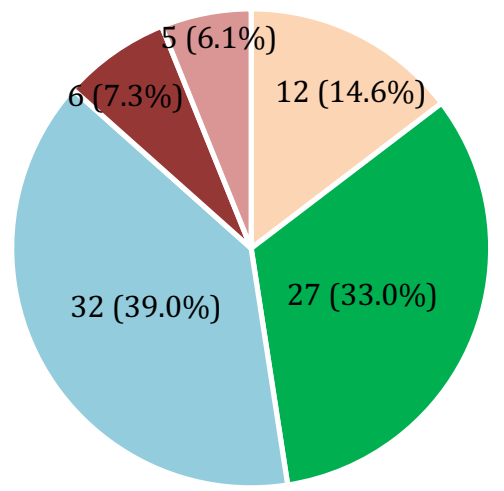

Significantly increased

- Moderately increased

- Stayed the same

- Moderately decreased

- Significantly decreased

Figure 4: Has your program budget significantly changed in the past three to five years (for reasons not related to COVID-19)?

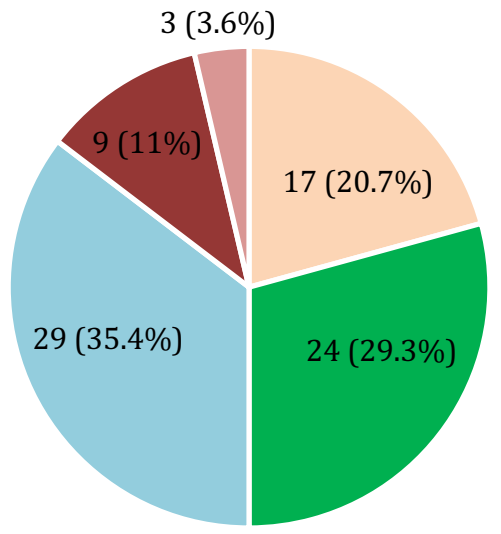

Significantly increased

- Moderately increased

$\square$ Stayed the same

- Moderately decreased

- Significantly decreased 


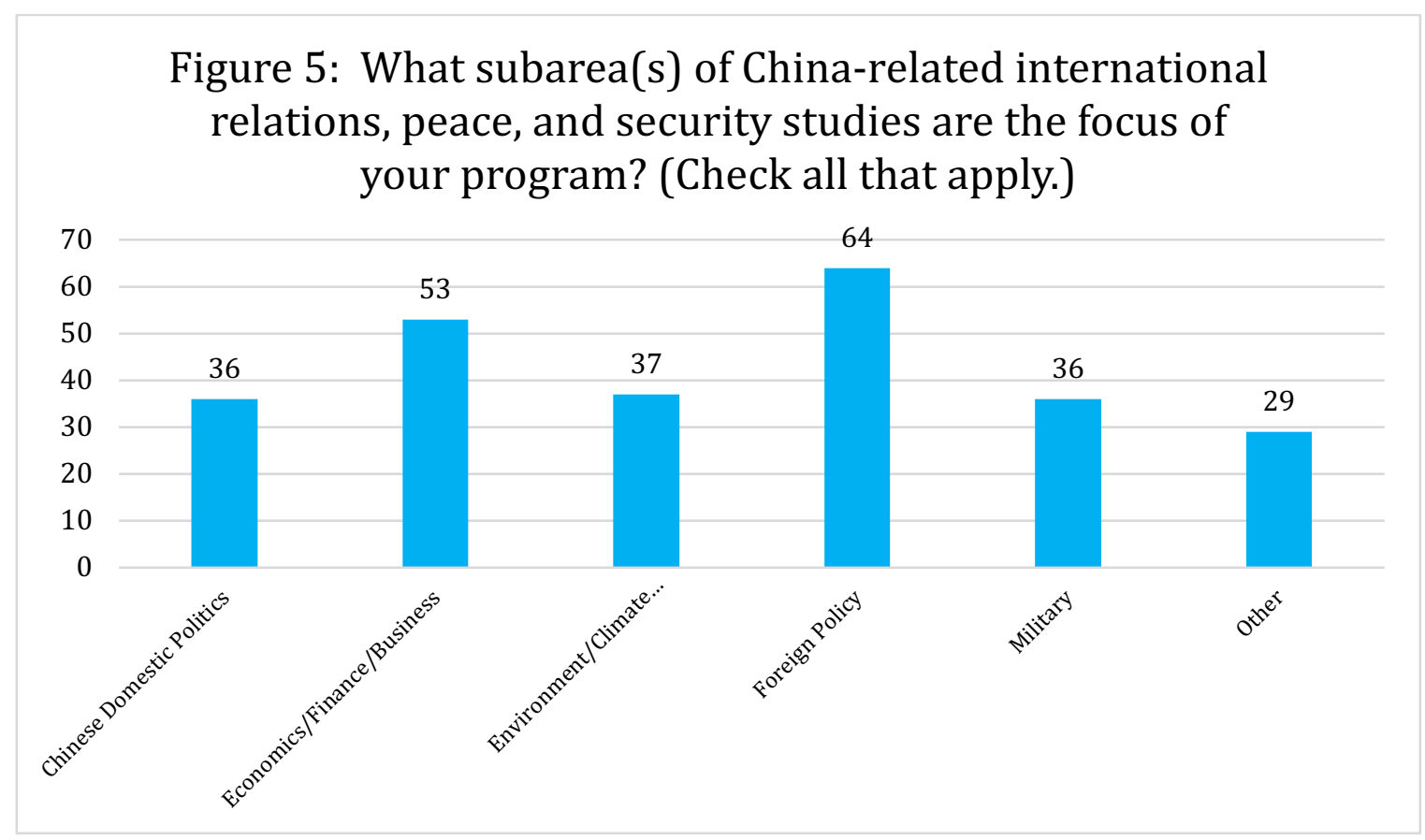

Figure 6: To what extent have changes in the U.S.-China relationship had an impact on your work?

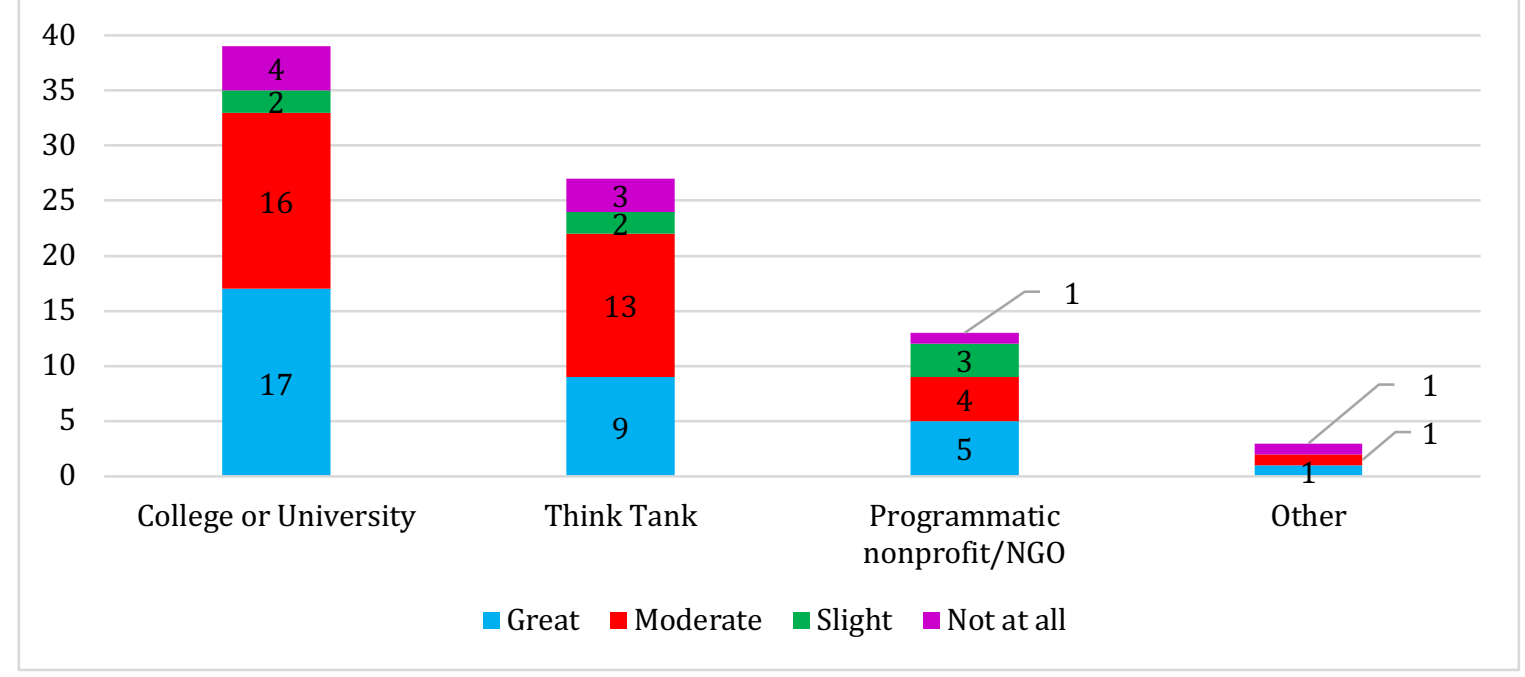



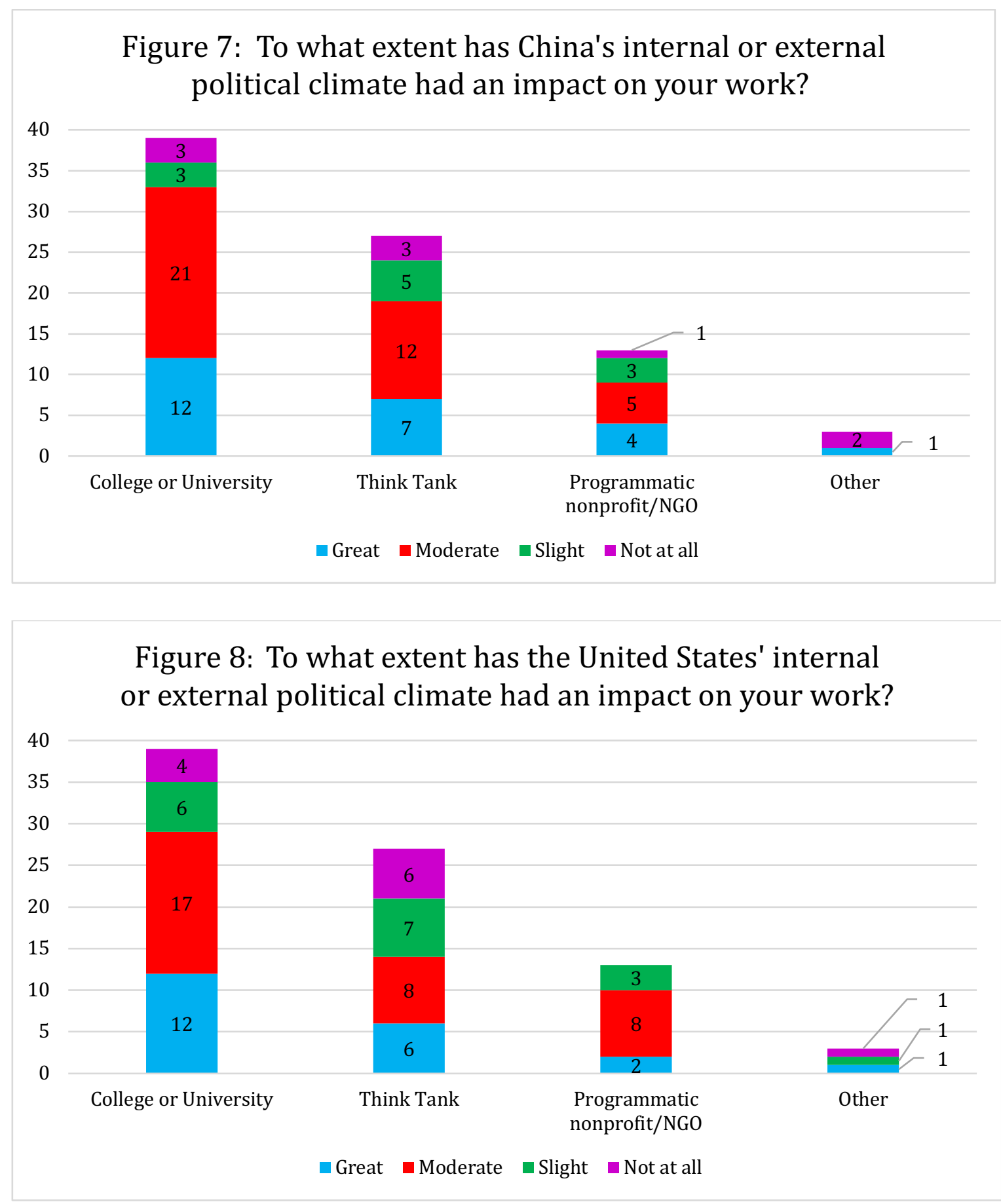


\section{KEY FINDINGS}

Key Finding 1: Demand for China content is growing in the United States, leading to an increase in opportunities for think tanks, programmatic institutions, and academia, along with a shift toward more public-facing work in the latter community.

- 40 respondents (48.8 percent) classified public education as a "high priority."

- 20 respondents (24.4 percent) cited some form of "growing interest in China/Asia" in their response to "What are the biggest opportunities for your program in the next few years?"

- 18 (46.2 percent) of the 39 university and college programs surveyed listed "public education" as a high priority.

In recent years, China has risen from a regional player to an important global power. The U.S. government and public are struggling to deepen their understanding of the PRC and are increasingly looking to China-focused organizations for help in doing so. In response, many organizations have modified their activities to meet the increasing demands of public and policy audiences.

Some respondents noted that increased alignment between their own research interests and the strategic interests of the U.S. government now yield more opportunities for them to contribute meaningfully to policy deliberations. One described "significantly greater interest in China-related national security issues," crediting "China's nationalist politics" for piquing the interest of funders and partners.

Several respondents noted that more public and government attention to China has meant increases in funding and hiring capacity. Additionally, many said that the remote environment in 2020 allowed them to reach wider audiences for events and programs than in the past. The inability to travel over the past year fortified many organizations' already-growing reliance on digital platforms.

Traditionally, the mandate of colleges and universities is teaching, research, and training successor generations of scholars - so their China centers' activities have been primarily intended for internal audiences. However, survey results indicate two trends in this community in the last few years: the production of more public-facing content (for both the general public and policymakers) and the establishment of semi-independent centers that are more nimble than traditional academic departments and can thus publish quickly and frequently, yet have the mantle of authority that accompanies academic expertise. Examples include Stanford University’s DigiChina, Georgetown University’s Center for Security and Emerging Technology, and the College of William \& Mary's AidData.

Respondents noted that increased attention to the field provides experts the opportunity to help shape the narrative. Many have seized the opportunity to brand themselves as China experts attempting to shape U.S.-China policy rather than participate in the much broader field of China studies. As one reviewer observed, "There has been a proliferation of self-identified China experts, but these are largely people interested in U.S. policy toward China and not providing a better understanding of China, even if to inform better policy." Ignorance and hostility on both 
sides of the U.S.-China relationship and China's rapid growth offer, as one respondent commented, a "once in a generation opportunity" for China specialists to assume the role of educators beyond the academy. "China's dramatic growth," the same individual continued,

... [forces] us to confront radically changing assumptions and international structures, processes, and dynamics which challenge us not only in how we think about China, but in how we think about everything from supply chains to human rights, from the Thucydides trap to dynamic coexistence, from global divisions of labor to enhanced competition, and from the unquestioned status quo of Western dominance of the past 300 years to the vast technological changes taking place in China.

Others noted that China's centrality in the foreign policy debate offers experts the opportunity to inject interdisciplinary approaches to the study of China. In addition, multiple respondents reported increased opportunities to collaborate with scholars and practitioners from a range of disciplines.

Key Finding 2: In China, domestic tightening has limited information flows, including access to data and the ability to conduct in-country research and interact with Chinese counterparts safely and effectively, influencing the topics that can be addressed productively.

- 17 respondents (20.7 percent) commented on difficulties obtaining visas or permission to go to the PRC in a scholarly or research capacity. ${ }^{4}$

- 17 respondents (20.7 percent) cited lack of access to data and Chinese sources as an impediment to their work.

- 13 respondents (15.9 percent) explicitly cited personal safety concerns as a deterrent to traveling to China.

Under President Xi Jinping, China's political environment has become increasingly restrictive, creating intellectual, moral, safety, and logistical impediments for many respondents.

Developments in Hong Kong (including the June 2020 National Security Law), continuing impact and resulting consequences of the 2017 INGO (international nongovernmental organization) law, and the overall climate of repression were all reported as specific challenges that pose barriers to conducting China-based research for practical reasons and concerns over personal safety. These challenges are most salient for the 36 respondents ( 43.9 percent) who reported organizing activities within China as part of their typical operations, but they affect others as well.

Many respondents cite an atmosphere of fear in China, which has resulted in a reluctance among Chinese nationals to speak openly with individuals representing American and other foreign organizations and to do collaborative research or programs. As a result of both Chinese counterparts' hesitation to speak and travel restrictions (visa- and coronavirus-related in both directions), U.S.-based researchers can no longer rely on traditional means of gathering evidence such as relatively free-flowing conversations, formal interviews, accessing archives, and other location-dependent research methods. President Xi's policies were cited as a specific reason for the tightening environment which is stifling traditional methods of data collection and research in China. One respondent commented, "We have growing concerns about our

\footnotetext{
${ }^{4}$ This includes instances where visa issues were named specifically, and mentions of related complications preventing researchers from traveling to China for research or work, including inability to receive invitation letters, or travel to China legally under the INGO law.
} 
ability to carry out our priorities in the face of the manner in which Xi Jinping is governing China."

Beijing's extralegal detentions of individuals have spurred safety concerns that inhibit some respondents' willingness to conduct in-country research. Several cited the Chinese government's detention of Michael Kovrig and Michael Spavor as a deterrent to China experts visiting the PRC, either out of fear that they, too, could be arbitrarily detained or as a protest against the detentions. Increasingly encompassing surveillance worries U.S. scholars concerned that their research findings and academic work could lead to political or personal safety risks for themselves, their family members, and/or Chinese interlocutors. As one respondent wrote, "The domestic Chinese political environment is so unpredictable as to make collaboration in China far too problematic to contemplate. We cannot risk detention."

As a result of the Chinese domestic political environment and the challenges it presents, respondents from across the institutions surveyed (universities, think tanks, and NGOs) reported an inability to conduct effective Track II dialogues, conferences, and other activities within the PRC. Many in the field also expressed an inability to engage in open, productive exchanges with Chinese officials and academics - privately or publicly. Even overseas, sometimes participation by Chinese interlocutors is seen as an obstacle due to the perception that they have to represent the government line. As one respondent wrote, "We also see a growing tendency to exclude Chinese scholars from some international fora because they are viewed as Beijing spokespeople whose views are known and whose presence stifles dialogue between international participants."

Tightening within China made a wide range of research methods, including data collection, interviewing, field work, and archival research, very difficult, and in some cases impossible. As restrictions imposed under President Xi have silenced many of their sources, ${ }^{5}$ researchers are less successful in finding individuals who are willing or able to provide context for CCP policies and the reality of their implementation. As a result, the Chinese government's narrative dominates.

In tandem, and in some cases as a consequence, the field is increasingly reliant on digitally available information that the PRC government releases to the public. These documents and datasets comprise only a subset of the whole; as it is in the CCP's interest to project strength and minimize its limitations, the articles, speeches, and documents that the Party is willing to provide publicly - and the select documents it translates into English - portray the government positively. Given these developments and researchers' increased dependence on digital research, Chinese-language skills (especially reading skills) are becoming more and more crucial. As a reviewer noted, "Chinese language ability is going to become more important as English-language materials from China lean more toward propaganda and access to experts inside China becomes more limited."

Some respondents reported adapting to the increasingly restrictive political environment in China by changing their approach to conducting exchanges. In response to the difficulty of conducting collaborative research with Chinese partners, some organizations are focusing on simply maintaining existing channels of communication. Many others are looking toward digitization. One respondent reported reacting to research impediments by "investing in digital scholarship and redoubling commitment to exchanges with all academics engaged in genuine

\footnotetext{
${ }^{5}$ As one respondent noted, "Chinese partners often have to perform with extreme caution."
} 
teaching and research." Others said that their inability to travel has served to fortify alreadygrowing reliance on digital platforms and clarified types of digital research opportunities.

But the prioritization of digital research to compensate for a lack of in-person contact comes with significant drawbacks. One respondent offered a critique of a methodological approach in the field "that favors survey methods and Internet-scraping which provides a better interface between the study of Chinese politics and the discipline of political science, but which discounts other, more traditional, inductive fieldwork-intensive or archival work." The same respondent wrote that this "niche-driven and micro-level" examination of Chinese politics, fortified by institutions' tenure and promotion criteria, has resulted in the prevalence of limited snapshots that fail to explicate the full picture of Chinese politics, and that this trend "will almost certainly be further driven by the decreasing level of direct access to Chinese data."

Key Finding 3: While often in response to specific Chinese actions and policies, the Trump administration's management of the relationship placed American foreign policy institutions and individual scholars focused on China in the cross fire, limiting their ability to successfully conduct research and programming.

- 54 organizations (65.9 percent) selected "greatly impacted" or "moderately impacted" for the question, "To what extent has the United States' internal or external political climate had an impact on your work?"

- 23 respondents (28 percent) reported visa-related and other travel restrictions imposed by the U.S. government as an impediment to their work.

- All programmatic NGO-affiliated respondents reported that the American political landscape affected their work to some degree.

Both U.S. and PRC policies have further compressed organizations' space to operate effectively. ${ }^{6}$ Visa and travel concerns for U.S. scholars going to China have been described in Key Finding 2; meanwhile, the December 2020 announcement of a visa ban on Chinese Communist Party members and their families was cited by multiple respondents as detrimental to their ability to operate normally. Respondents' frustration was exacerbated since these obstacles to exchange, particularly those propagated by the White House, occurred at a time when strengthening American understanding of the range of Chinese thinking has become crucial.

More fundamentally, the administration's combative approach to the relationship influenced American news and commentary on China and prompted a focus on confrontation and competition. A respondent wrote that some America-based media coverage of China "tends to be political and propagandist" rather than based on informed assessments. Respondents also described a proliferation of biased or unverified information about China circulating in recent years, given added prominence by a variety of factors: social media, the ease with which incomplete or unfounded analyses can be shared online, and the Trump administration's perpetuation of false claims about China. These factors combined to intensify experts' sense of obligation to counter the overarching media narrative on China.

\footnotetext{
${ }^{6}$ In 2020, the Trump administration suspended the Fulbright program in Hong Kong and China and closed the Chinese consulate in Houston, Texas, which Secretary of State Mike Pompeo described as "a hub of stealing and intellectual property theft." Days later, in response, China's Foreign Ministry announced the closure of the U.S. consulate in Chengdu.
} 
Aggressive U.S. policies during this period were also seen as contributing to a destabilized geopolitical landscape. A number of respondents believe that some of these policies, whether domestic or foreign, have undermined their work. One described how the administration's approach directly affected the China studies field:

On the U.S. side, our greatest challenge has been countering the antagonistic and highly personal approach which the Trump administration has taken to foreign affairs.... Trump's style and actions have made it difficult to engage with Chinese interlocutors, who often feel aggrieved by the latest overstatement from Washington and wish to focus on that rather than on long-standing, structural issues in the relationship that would tax both sides' intelligence even if Trump were not president.

In many ways, American China-focused organizations have been collateral damage of the United States' increasingly polarized debates and policy decisions, and their international reputational harm. For example, American organizations, especially those in the advocacy and legal spheres, have been affected in recent years by the U.S. government's inconsistent approach to human rights. One respondent wrote that the previous administration's "indifference to human rights principles has somewhat weakened our standing in advocating for China's adherence to those principles." Another echoed this sentiment, writing. "The rise of nationalism and populism in the Trump era, along with political polarization, has undermined several of the premises of our work: the value of U.S. engagement in multilateral institutions and with allies and non-allies alike; the ability to advance bipartisan policy solutions; and, frankly, the trustworthiness and credibility of the United States in global affairs."

Key Finding 4: The downturn in the bilateral relationship has politicized work on China and constrained organizations by severely polarizing discussion of China and Sino-American relations, resulting in a diminution of the quality of the discourse in both countries.

- 26 respondents (31.7 percent) reported the increasingly polarized U.S. policy and rhetoric on China as having a direct negative effect on their work.

Over the last four years, U.S. government officials have found very few areas of bipartisan agreement; the need for America to take a harsher stance against China is one of them. At the precise time that respondents' work explaining contemporary China is most essential, there is little appetite on the part of the nonexpert community for arguments that deviate from the status quo of vilifying China. As a respondent reported, "the toxicity of the current climate has led to a debasement of analysis, favoring arguments that are flashy and fear-inducing over more sound, rational, long-term thinking that could help the U.S. navigate its way forward in a complex, consequential, and inescapable relationship with China."

U.S.-based China-related organizations' missions and mandates have been threatened by polarization, nationalism, and hostility coming from both sides of the relationship, which in some cases pose existential threats to their programs. One respondent wrote that the breakdown in communication between the United States and China required "retooling our research approaches, recalibrating our student trips, and pushing back on the simplistic narrative emerging about China and its global ambitions, while finding our access to Chinese counterparts and interlocutors increasingly and unnecessarily curtailed." Another noted, "The worsening of the U.S.-China relationship has politicized this research in ways that I have not seen in my own career." 
Constraints on research impede scholars' ability to understand the overall context of Chinese policies. There is a risk that a U.S. consensus based on incomplete assessments will emerge, especially regarding the threat posed by Chinese government actions. Although much research relies on Chinese-language documents to understand the CCP's ambitions, according to one respondent these analyses sometimes lack "nuance or understanding of how Chinese language documents often are in discussion with each other and do not represent a single, authoritative view." Presentations of these documents as indicative of the entirety of China's plans has, according to the same respondent, "led to an over-inflation of the China threat and an underappreciation of the significant challenges China will confront in the coming decades."

Other respondents reported that neutral analyses often seem unwelcome by external stakeholders, including American policymakers. Some articulated an increasing difficulty for American scholars to discuss China issues without taking a stance, reporting "hostility toward even principled engagement with China." There is a feeling among respondents that balanced research on China is "under attack" and in need of defense; one respondent wrote, "polarization of the field may pose a daunting challenge to our community." Another respondent echoed this sentiment, writing. "We are a part of the late-20th century wave of globalism, trying to promote the better part of globalism during a resurgence of tribalism."

Polarization in the American discourse has also affected Chinese and Asian-American scholars and has led some to fear for their personal safety in the United States. Others were concerned about the safety of students amidst the sharp rise in politically fueled racism against Chinese, Chinese-Americans, and other Asian-Americans that many partially attribute to increased racist rhetoric regarding the coronavirus pandemic used by politicians and public figures since February 2020. These concerns were echoed by a respondent who cited xenophobic and antiChina sentiment in the United States as one reason measured discussion of China has become very difficult. Political hawkishness toward China was also described by a respondent as problematic for the field, and as one respondent observed, "has been making many China scholars cautious and nervous." The same respondent continued, "These scholars who study China or work on U.S.-China issues are afraid that their publications, academic work and opinions may attract trouble for them within the U.S. This has been one of the saddest developments in recent years."

Despite the many challenges it presents, polarization has also offered opportunities for those in the field to educate government officials and the American public, in the interest of providing a balanced perspective. One respondent directly addressed the important role academia and China-focused organizations play in this area, writing, "We have potentially a huge role in explaining/interpreting/warning a broad public." Some respondents advocated for expanding U.S.-China engagement at the subnational level as a way of circumventing the tensions between Beijing and Washington. Another described leading with the data, aiming to make sense of what it says on its own rather than proving a preexisting political agenda, adding, "In an increasingly combative discourse on China, that commitment is rare and, we hope, makes us a trusted resource and reference point across the political and ideological spectrum."

Key Finding 5: In the current U.S. geopolitical environment, many China-related topics are viewed through the lens of security, both within and outside academia. As a result, China has been reduced to a target in U.S. domestic rhetoric, rather than a complex subject of multidisciplinary study. 
- Among the 67 respondents (81.7 percent) who labeled research a "high priority," 30 of them (44.8 percent) included China's military as one of their areas of focus.

- Among the 10 organizations (12.2 percent) that reported receiving more than 50 percent of their funding from the U.S. government, military, security, and human rights issues pertaining to China were their primary areas of research and engagement.

Although the notion that China is an adversary is not new, it was solidified by the 2018 classification of China as a strategic competitor in the National Security Strategy. While China's more aggressive domestic and foreign policies predate the Trump administration, ${ }^{7}$ many of the increasingly assertive actions of President Xi and the CCP leadership in recent years overlapped with President Trump's term in office. These actions largely center on border issues and territorial claims, including actions in the South China Sea; ethnically and religiously targeted detentions and abuse of Uighurs and other Muslims in Xinjiang; disputes and conflict along the China-India border; repression and extralegal detentions in Hong Kong; and increasing military activity and threat levels in the Taiwan Strait.

One respondent described how bipartisan hawkishness on China during this period has affected the field:

Hard-line views in Congress and the instinct to try to counter every egregious Chinese act with American legislation - much of which is useless or counterproductive - has also made our task more difficult, as many legislators seem to think that any attempt to bring complexity to discussions of U.S.-China relations stems from a soft hand or a soft head. Expertise is often viewed as blinkered or gullible.

This security-focused interpretation of China's actions, however, has not been entirely negative as it has identified genuinely understudied threats and brought new specialists to the field. One respondent commented, "We have a number of national security professionals and faculty whose work increasingly involves aspects of China policy by virtue of China's growing emphasis in U.S. national security considerations and strategy."

There is a fear, however, that security considerations now overshadow other areas of research. As one respondent noted, "The security community's approach to U.S.-China relations now dominates the conversation, blinding both sides to the full potential of relations and to possibilities for cooperation and co-evolution." Excessively prioritizing security and pouring a lot of money into security-related areas, ${ }^{8}$ paradoxically, may create a self-fulfilling prophecy wherein threat is the only lens through which each country assesses the other. Despite real concerns posed by the CCP's actions, respondents fear a narrow focus on China's role as a competitor reduces it to a target, rather than a complex subject of multidisciplinary study.

Some respondents feel the Trump administration responded too narrowly to China's external political, espionage, and influence activities. The administration's inattention to nontraditional security threats present in the relationship and its excessive attention to maintaining American hard power preeminence in Asia only address one part of the problem. A reviewer pointed out that the majority view within the American foreign policy community is that a more diverse and

\footnotetext{
7 This was reflected in President Obama's "pivot to Asia" policy and subsequent policies.

${ }^{8}$ As one respondent wrote, "I think we need to watch the flood of potential DOD funding and [the] distorting effect it may have across research institutions."
} 
dynamic foreign policy tool kit is needed, and military action should be avoided at all costs. One respondent explained that the field lacks adequate consideration of nonmilitary forms of crisis prevention and alternatives to American military dominance in the region, calling this a byproduct of 20th-century ideological and military competition, and groupthink regarding a long-term security strategy in Asia.

On the other hand, some organizations have both supported and benefited from the China field's tilt toward security. One respondent wrote, "Intensifying concern in the U.S. about strategic competition with China, malign foreign influence, and strengthening democratic resilience in partnership with allies has been a boon to our work." Despite this increased attention to security and competition, there remains a dearth of thorough and detailed research on China's military; as one reviewer wrote, "Even in think-tanks, there are few 'PLA watchers' (though perhaps many PLA commentators) who use Chinese sources to understand the PLA. As China now spends more on defense than any country other than the United States, more work is needed on these issues from academics."

Increased attention on China as a security threat has resulted in the outsized influence of countless new so-called "China experts"; as one respondent wrote, "Many experts from a variety of fields now have influence on China policy, but not all have actually studied China." Without a strong foundation of language study and extended time in the field, these experts can speak to pertinent topics within their areas, but may lack in-depth understanding of China. As a reviewer said, "Everyone is a China expert these days. Or wants to be." The rise of these voices has added to the "chorus" of experts focused on China's role as a security threat to the United States. 


\section{SUCCESSES AND CHALLENGES}

\section{Successes}

As noted in Key Finding 1, opportunities have increased as interest in China has expanded, generally providing more fodder for organizations old and new to rethink their work. Issues of relevance to the U.S.-China relationship now include areas that were previously seen as niche subfields, such as China's domestic economic and technology policies, expanding the security field beyond China's foreign policy, military-to-military relations, and strategic outlook. New organizations have cropped up to address the need for deeper research, publication, and policy guidance on these topics.

In the past decade, new organizations were also created to address challenges posed by the American political environment. The Quincy Institute for Responsible Statecraft, for example, was established in 2019 with support from prominent funders on the American political left and right in order to promote the view that foreign policy issues should be oriented toward diplomatic solutions rather than conflict. The Black China Caucus, established in 2020, aims to diversify the field and promote the voices of experts among people of color; it attributes its significant growth to the Black Lives Matter protests that took place in 2020.

Established organizations cited ongoing efforts to adapt their practices by producing more policy-relevant work, increasing public programs, and/or reworking strategic plans to account for the new context. Many university-based China centers expanded their scope beyond internal on-campus audiences to inform the general public and policymakers.

In general, organizations have found ways to collaborate and coordinate with Chinese colleagues and counterpart organizations despite the logistical and political obstacles present in those endeavors. It should not be a surprise, however, that those that reported the most success in doing so are in the climate and energy fields lareas where China has made public declarations of its intent to cooperate) and those working specifically on technical issues.

Methodological and other approaches listed below constitute the primary types of successes reported by respondents:

- Nuanced and nonpoliticized publishing and research on China, contributing in a neutral way to the discourse, producing policy-oriented work that is based on a deep understanding of China

- Working with Chinese counterparts on specific, practical projects, especially on environmental issues

- Emphasizing data-driven research approaches ${ }^{9}$

- Dialogues and exchanges - while growing increasingly difficult to run productively, these remain a vital component of U.S. organizations' work on China

\footnotetext{
${ }^{9}$ One respondent described developing a program that publishes "field-altering research that quantifies difficult-tomeasure concepts such as China's public diplomacy toolkit" and is "on the frontline of producing new insights in traditionally data-poor areas."
} 


\section{Challenges}

Responses elucidate a continuing concern about the narrowing pipeline of younger scholars who are comprehensively trained, and who can continue the work of older cohorts, some of whom are retiring or will be in the coming few years. Others fear that the climate in China will deter new scholars from entering the field and replenishing the pipeline. ${ }^{10}$ One reviewer's comment represents that of several: "I suspect that the political climate in China ... will not improve that trend, but probably exacerbate it and make it worse."

Multiple respondents brought up diversity as an issue in the China studies field. One respondent summed it up:

The field lacks diversity in the extreme, which not only limits opportunities for a wide range of potential future leaders, but also narrows the ideological spectrum of the field and impedes creative thinking. Organizations that promote expert opinion must broaden their definition of "expert" to ensure they continue to inject fresh thinking into the field of China's relations with the rest of the world. We shouldn't be surprised that this area of study was susceptible to groupthink, and we should quickly appreciate that the solution to this problem isn't a unified pivot towards a new consensus, but rather to evolve the system so that it includes a wider range of ideas and voices.

Several respondents expressed concern about the future of the China field beyond the pipeline issue. Given the context of increased tightening in China, there continues to be debate regarding how research approaches and methodologies can or should be altered. Specific issues such as the Chinese government's handling of minority politics and international diplomacy have become increasingly securitized in the U.S.-China relationship, which some respondents believe has underscored the need for improved basic research in these areas. One reviewer called for increased funding for long-term qualitative research to answer questions such as "what exactly is China doing, where, and to what extent is that behavior indicative of change or continuity from the past?"

Achieving this counterbalance is increasingly important as professional incentives and geopolitical challenges push the field further in the other direction and may hold existential challenges to its legitimacy. One respondent noted that in the United States, "The field of China studies and U.S.-China relations is no longer the best in the world, it has significantly deteriorated in the past decade. It will lose its credibility in general unless we make strong efforts to correct its dogmatism and self-indulgence."

A few institutions found the increased interest in China and their success in responding to it had brought with it sufficient attention to make fundraising easier than in the past. However, in general, financial constraints permeate the field. American political and popular attitudes toward China have negatively affected the type and degree of funding available to most of the surveyed organizations. Several reported simultaneously confronting increases in the demand for China-related research and the financial inability to hire accordingly. Others found that an ease in fundraising at times comes with strings attached. One respondent wrote, "I am very concerned about the extent of U.S. government funding going into certain research niches on China that have not typically been heavily government funded and tend to produce negative exposé reports." Others emphasized that unbiased funding deliberations are made by only a

\footnotetext{
10 The political environment in China may already be affecting foreign students' willingness to study abroad in China.
} 
handful of foundations and expressed concern that looking for funding beyond this small group can be troubling since both the corporate world and the U.S. government, not to mention foreign governments, have their own agendas.

\section{Research Gaps}

The survey asked respondents to identify major gaps in research or programmatic work in China-focused foreign policy organizations. Some of the gaps, such as China's international engagement, conflict avoidance, and relationships with third countries, are not new. However, there is a noticeable expansion from similar surveys conducted in the past in the range of relevant issues. Categories of research gaps mentioned by respondents are listed in alphabetical order below:

\begin{tabular}{|c|c|}
\hline Category & Gaps in Research \\
\hline China's International Economic Engagement & $\begin{array}{l}\text { - China's continuing trade expansion } \\
\text { - U.S.-China economic interdependence } \\
\text { and how it contributes to American } \\
\text { and Chinese interests and the stability } \\
\text { of the global economy } \\
\text { - China's use of economic engagement } \\
\text { as potential leverage in other arenas }\end{array}$ \\
\hline $\begin{array}{l}\text { China's Relations with Countries Other Than } \\
\text { the United States }\end{array}$ & $\begin{array}{l}\text { - China's relationships with Russia and } \\
\text { India } \\
\text { - China's relations with Latin America } \\
\text { and Africa, including its } 20 \text {-year } \\
\text { history of intensifying relations in } \\
\text { Africa and implications for U.S. } \\
\text { interests }\end{array}$ \\
\hline Document Access & $\begin{array}{l}\text { - Ability to access original Chinese } \\
\text { documents, articles, commentary, and } \\
\text { speeches } \\
\text { - Open-source translations of these } \\
\text { documents }\end{array}$ \\
\hline Emerging Technologies & $\begin{array}{ll}\text { - } & \text { Artificial intelligence and } \\
\text { cybersecurity } \\
\text { - } & \text { Chinese science and technology policy } \\
\text { - } & \text { Technological decoupling } \\
\text { - } & \text { Technology governance and standard- } \\
\text { setting } & \\
\text { - } & \text { Biotechnology and biomedical security } \\
\text { - } & \text { China's technological prowess in } \\
\text { terms of both domestic power } \\
\text { - } \quad \text { How major tech companies constitute } \\
\text { enormous nonstate power centers in } \\
\text { many global contexts }\end{array}$ \\
\hline
\end{tabular}




\begin{tabular}{|c|c|}
\hline & $\begin{array}{l}\text { - Power dynamics between individuals } \\
\text { and companies and between } \\
\text { companies and governments }\end{array}$ \\
\hline Nontraditional Security Studies & $\begin{array}{l}\text { - Environmental security, public health, } \\
\text { and human rights issues across the } \\
\text { board } \\
\text { - } \quad \text { China's } 2060 \text { carbon neutral goal } \\
\text { - } \quad \text { A realistic plan for constructive } \\
\text { competition within the U.S.-China } \\
\text { climate relationship } \\
\text { - Human rights work across a variety of } \\
\text { fields (global economics, international } \\
\text { relations, climate change) }{ }^{11} \\
\text { - Centrality of climate change in peace } \\
\text { and security and international } \\
\text { relations } \\
\text { Management of the U.S.-China } \\
\text { relationship in the context of the } \\
\text { shared existential threat of climate } \\
\text { change }\end{array}$ \\
\hline Understanding Chinese Domestic Politics & $\begin{array}{l}\text { - China's efforts to "export" its model } \\
\text { and China's role as an "international } \\
\text { regime-shaper" }\end{array}$ \\
\hline
\end{tabular}

\section{Needs of the Field ${ }^{12}$}

Respondents also identified methodological areas and research approaches that they believe are insufficiently represented in the China studies field.

Access: The inaccessibility of interview subjects and other Chinese interlocutors, increasing logistical difficulties to conducting field work, and closing of archives to scholars were reported as impediments to effective research in the current political environment. Also mentioned is the fact that insufficient attention is paid to the work of Chinese scholars based in China.

Chinese Ethnic Minority Studies: Respondents described problems in both the quantity and quality of research related to religious and ethnic minority affairs in China, an area one respondent called "marginalized." A stronger grasp of Chinese minority politics, institutions, and languages as well as more nuance regarding the Chinese government's attitudes toward minority affairs is needed among many who write on the subject.

\footnotetext{
${ }^{11}$ One respondent described the elevation of human rights in geopolitical concerns this way: "The international developments and shifting views among diverse stakeholders regarding the importance of the human rights perspective and normative tools [presents an opportunity], as the inclusion of human rights work in this survey reflects."

12 The needs here are also listed in alphabetical order.
} 
Diplomacy "as a tool of statecraft": Chinese diplomacy, according to one respondent, is currently insufficiently studied as its own subject of inquiry. This area would include how China engages with countries around the world and how they respond to China's approach. As one reviewer wrote, China's diplomacy "is often simply subsumed under the idea that China has been more assertive without actually unpacking how China practices the art of diplomacy, to include how it bargains/negotiates with other countries, how it structures its foreign relations bilaterally and multilaterally, regionally and globally, [and] the ideas behind its diplomacy."

Educating Non-China Specialists: One reviewer wrote, "I believe the field now also needs to think carefully about how to provide training on analyzing and interpreting China to security/conflict scholars who will not become full Sinologists, but whose work will definitely shape China policy and U.S.-China relations."

Managing Risk: There is a clear need for researchers, especially those conducting field work, to acquire a personal and professional risk tool kit that would include practices similar to those adopted by researchers who have faced similar challenges in different geographic regions. ${ }^{13}$

"Return to Sinology": Respondents expressed the necessity of strengthening area studies expertise and language skills in general, and specifically, to interpret Chinese documents in their appropriate political context, and to reflect complex political realities in China such as the competing interests of various factions within the Party.

Translation: Open-source translations ${ }^{14}$ of Chinese documents, expanding from technical translations (the field's primary area of translation success), and offering a wider sampling of more general political translations, was cited by respondents as an area in need of expansion and contextualization.

\footnotetext{
${ }^{13}$ Contemporary best practices could be adopted from scholars focused on the Middle East, or historic examples may be found in the study of the USSR.

14 Websites such as NPC Observer, Reading the China Dream, and China Law Translate are noteworthy projects which seek to expand availability of open-source translations in specific areas.
} 


\section{CONCLUSIONS}

As China's domestic and foreign policies continue to attract widespread attention among Americans, respondents emphasized the importance of keeping the discourse fact-based, rational, and productive. To achieve this end, it is crucial that China scholars help experts from other fields better understand China; by the same token, scholars and practitioners from other fields can strengthen China experts' grasp of other research areas. According to a reviewer, "The broadening of China conflict/security work beyond people whose primary training focuses on China is a challenge - because it could lead to flawed analysis. But it also presents an opportunity for funders and educators: there is a whole new set of people who could benefit from learning how to study China well."

Immense uncertainty characterized the survey findings in this report. COVID-19 and political unknowns on both sides of the Pacific made it impossible for many organizations to conduct business as usual in 2020 . While the unpredictability faced by respondents has been described elsewhere in this report, it bears repeating due to the dominant role it played in their assessments. Survey results also strongly reflect increased attention to China throughout American government and society and the resulting impact - positive and negative - this attention had on the field.

Multiple respondents indicated their frustration at the difficulty of hearing directly from Chinese interlocutors, thus rendering nuanced discourse extremely difficult. This has been exacerbated by the fact that the Chinese government has expelled many foreign correspondents who previously conveyed some of those voices through their reporting.

It is clear the field has shifted markedly since NCUSCR last surveyed American organizations focused on China and peace and security studies nearly 10 years ago: experts in advanced technologies (as they relate to China from political, economic, and security perspectives) have emerged; risk and safety have now become significant features of the field; concerns over lack of cross-pollination within the field have been overshadowed by fear of groupthink; and many agree that there is now a more intense focus on strategic and security-related issues in studying China.

While respondents did not expect a significant shift in U.S. policy toward China under the new administration, many speculated that President Biden would likely approach the relationship with a more consistent and less hostile tone. They were hopeful that such a change might allow for more opportunities for multilateral coordination on China and a resumption of people-topeople exchanges. The ways in which the political environment within China - and potential research opportunities - may develop remain to be seen.

Whatever the new administration's policies may be, survey results demonstrated respondents' alarm at the burgeoning gulf between the two countries and how this divergence will continue to stifle research and exchange. These fears were compounded by the fast-closing windows for exchange that came as collateral damage of the COVID-19 pandemic. Despite these challenges, respondents made it clear that they anticipate that the role and relevance of research on many aspects of Chinese governance and society will, and indeed must, continue to expand in the United States. 


\section{APPENDIX}

List of Organizations That Responded to the Survey

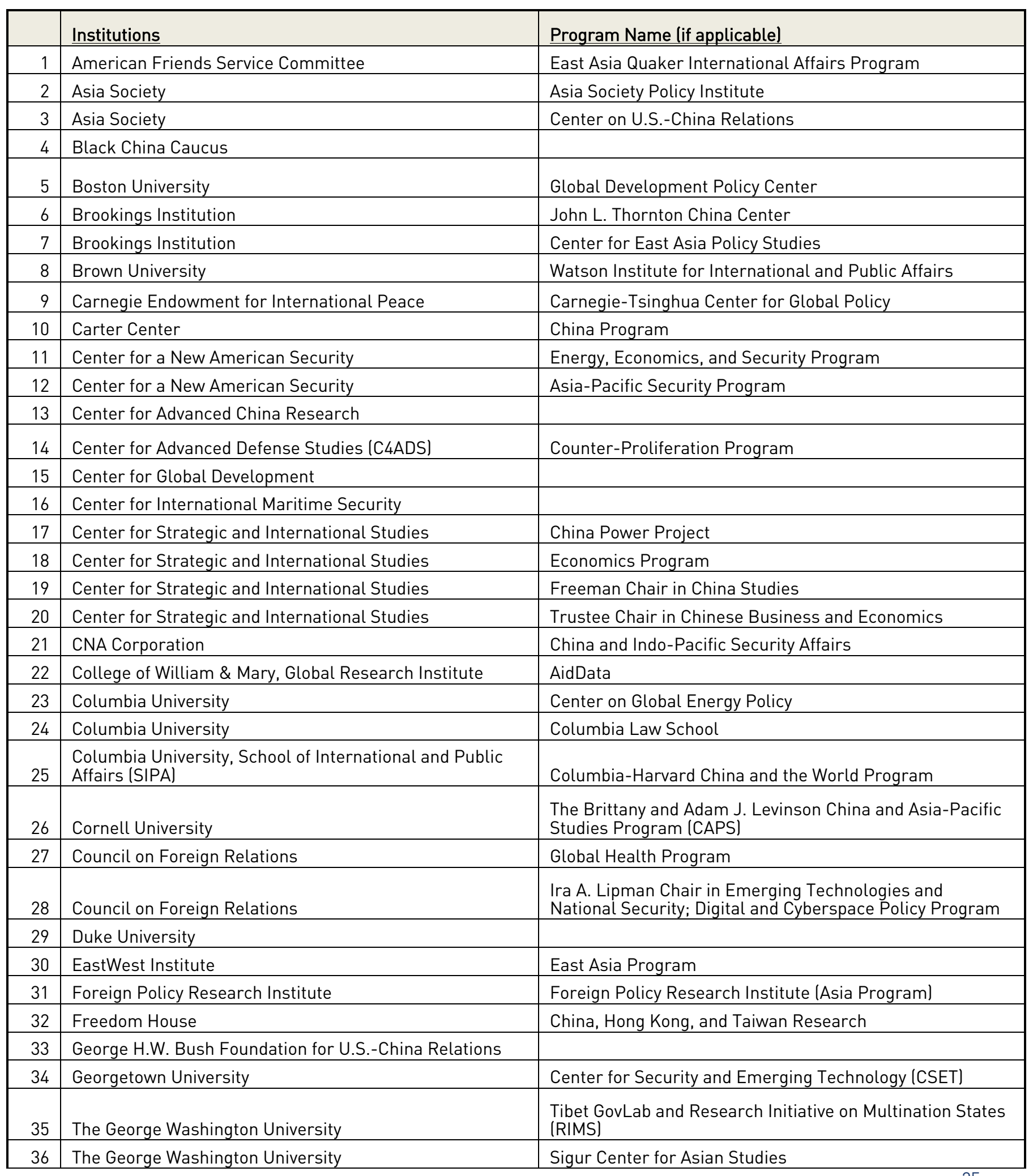




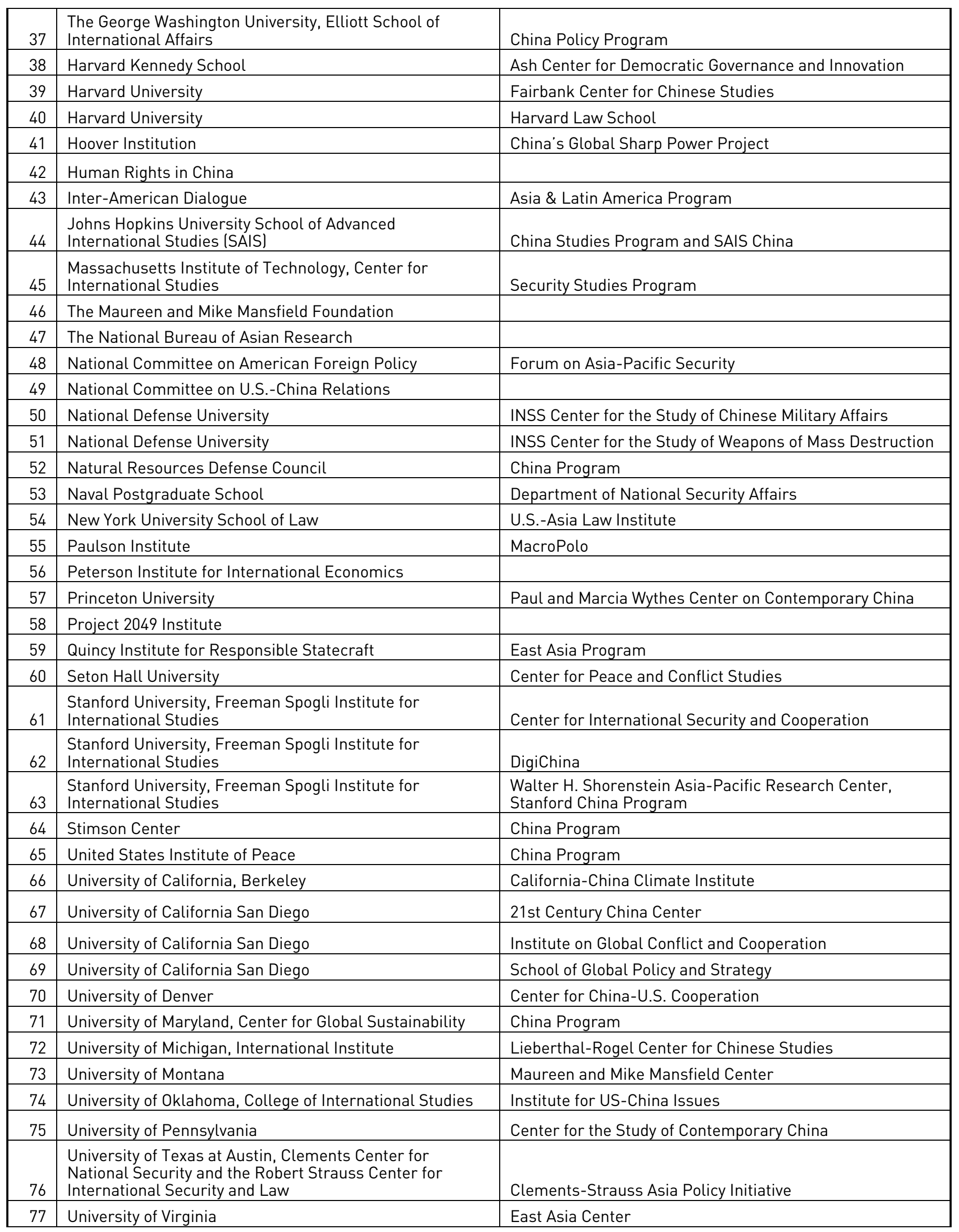




\begin{tabular}{|r|l|l|}
\hline 78 & $\begin{array}{l}\text { University of Washington, Henry M. Jackson School of } \\
\text { International Studies }\end{array}$ & China Studies Program \\
\hline 79 & U.S. Air Force & China Aerospace Studies Institute \\
\hline 80 & Woodrow Wilson International Center for Scholars & Asia Program \\
\hline 81 & Woodrow Wilson International Center for Scholars & Kissinger Institute on China and the United States \\
\hline 82 & World Resources Institute & Climate Program \\
\hline
\end{tabular}

